\title{
Assessing the Helpfulness of School-Based Mentors in the Nurturing of Student Teachers' Professional Growth on Teaching Practice
}

\author{
Ndileleni Paulinah Mudzielwana \\ University of Venda, South Africa \\ Cosmas Maphosa
}

University of Fort Hare, South Africa

\section{Doi:10.5901/mjss.2014.v5n7p402}

\section{Abstract}

The study sought to assess the helpfulness of school-based mentors in the nurturing of professional development of student teachers on teaching practice. The study adopted a qualitative case study design in which a purposeful sample of twenty-five final Bachelor of Education students participated. Open ended questionnaires were used as the main and sole data collection tool. Content analysis was used to analyse data thematically after coding. The study found that school-based mentors were generally helpful to student teachers in numerous areas ranging from record making and keeping to classroom management. There were concerns of some mentors who only waited for students to ask for assistance. The study concluded that attaching trainee teachers to mentors is a good approach which could be further enhanced by adequately preparing mentors for their roles. Recommendations are made.

Keywords: Mentors. Professional growth. Student teachers. Teaching practice.

\section{Introduction}

Teaching practice is a very important component of any teacher training programme (Maphosa, Shumba \& Shumba, 2007; Kiggundu \& Nayimuli, 2009). It is during teaching practice that student teachers learn the art of teaching by turning theory into practice (Price, 1998). During the teaching practice stint, student teachers work in schools and their progress is monitored and evaluated regularly. A pass in teaching practice is a prerequisite for graduation together with passes in other courses or modules.

Teaching practice is quite a challenge to many student teachers and this view is shared by Groundwater-Smith (1993:137) who observes that:

The practicum experience is one fraught with difficulties, dilemmas and challenges as the student attempts to negotiate his or her way along a hazardous path of professional policies and practices.

Such challenges can only be minimised if student teachers get proper guidance whilst on teaching practice. Guidance is offered by senior professionals in the schools. Koerner (1992) notes that the quality and success of teaching practice depends on the role and effectiveness of the mentors guiding the student teachers.

\subsection{Mentoring}

Mentoring is a nurturing process, in which a more experienced person, serving as a role model provides professional assistance to the student teacher. This implies that mentoring is more than giving advice and passing on experience, instead, it is about encouraging the students and empowering them so that they can become more competent in their practice.

Callan (2006:6) describes the qualities of the 'ideal' mentor as:

Good humour, enthusiastic, inspirational, problem solver, supportive, knowledgeable and competent in subject skills and practices, creative thinker, good communication and interpersonal skills, good partner skills, able to resolve or defuse conflict, effective time manager, prioritises and sets targets, action plans, report writing, 'politically' astute 
beyond the immediate context, reflective.

This shows that an effective mentor should possess numerous positive attributes that will enable him or her to work effectively in the mentoring role.

Doherty (1999:6) defines a mentor as:

... a person who oversees the career and development of another person, usually a junior, through teaching,
counseling, providing psychological support, protecting, and at times promoting or sponsoring.

This implies that the mentor has a crucial and multi-faceted role and performs multiple functions during the mentor relationship. It is also clear that a strong relationship between the mentor and the mentees is of critical importance. Both the mentor and the mentee should understand that the objective of their relationship is to promote professional readiness to the student. Mentoring can take a formal or informal relationship. However there are differences between the formal and informal mentoring relationship. In an informal mentoring relationship the mentor provides teaching materials, classroom teaching strategies, and unit and long-range plans for the benefit of the protégé (Alberta Teachers' Association (ATA), 2003: 4).

Formal mentorship entails the act of two people engaging in an organized, systematic relationship of providing and receiving assistance and insight (Mel, Heller \& Sindelar, 1991:6). Mel, Heller and Sindelar (1991) state that in this relationship, the mentor may share materials but also goes beyond the sharing and moves into the development of materials within a collaborative team. This requires reflective practice, collaborative planning and action research coupled with a joint action plan by the mentor and protégé. As Garvery (2000) cited in Alberta Teachers' Association (ATA) (2003) asserts, the mentoring process allows both mentor and protégé to grow and develop professionally.

The mentor is not supposed to be a problem solver or a judge of the mentee's opinions. Chubbuck, Clift, Allard and Quinlan, (2001) advise that a mentor's task is to question the mentee in order to support the learning and reflective process. Lick (1999) and Alred and Garvey (2000) stress that a special goal with mentoring is to contribute to learning. To make that happen the mentee as the learner, ought to be engaged and have a constructive self-awareness.

\title{
1.2 Role of mentors
}

One key quality to successful mentoring appears to be the mentor/mentee relationship itself (Gray and Gray, 1985). Timperley (2008) states that educational leaders such as school-based mentors should show the way and should be 'powerful catalysts' for student teachers to develop professionally. Kram (1983) cited Alberta Teachers' Association (ATA) (2003:30) identifies four important phases of the mentorship relationship namely initiation (where mentor and mentee get to know each other), cultivation (developing understanding and parameters of operation), separation (allowing mentor's role to decrease and mentee's to increase) and redefinition (assessing the progression of the mentor-mentee relationship). The researchers believe that university lecturers should have a knowledge base to prepare and plan the mentoring programme for the mentors so that it can be beneficial to both the students, mentors and the learners in the classroom.

Mentors should also engage mentees in various aspects of their duties. Such a view is consistent with a view by Fisher, Higgins and Loveless (2006:2) that 'teacher learning is an active, experiential process, through which knowledge is enacted, constructed and revised.' It is very much important that student teachers should be actively involved in learning from the mentors by engaging in discussions and asking questions for clarification inside or outside the school in order to widen their scope of knowledge and have an interest in reading literature by various authors. This habit will add more on what they will get from mentors. It is also critical to be creative and exploratory and this will take students to achieve what they expected.

Hansen (2001:734) states that:

\begin{abstract}
For teachers and teacher candidates, engaged as they are in time-honoured, immensely significant moral endeavour, it seems crucial to create regular opportunities for talking about what matters most in the practice. Such opportunities, whether inside or outside the school, make it possible for teachers to talk their way more deeply into the role, so that they can take on the role that much more and shape it in ways that serve both their students' and their own development.
\end{abstract}

Clearly student teachers should be committed and willing to learn by sharing ideas with the more experienced individuals; who will expose them to what is right and wrong and what is expected of them as professionals. Student 
teachers must be aware that teaching is a process and that one of their roles is to become life-long learners. This is because teachers are agents of change, so they must always be up to date on what is happening in education. Vossler (2006:29) states:

One has never 'become' a teacher as in the completed journey, a sense of arrival or acquiring a qualification, but rather 'becoming' a teacher is a journey undertaken collectively and collaborately with others in a community of practice and a community of learners.

Therefore, it is necessary that student teachers should undergo the process of teaching practice, have a relationship that is characterised by trust and learn from the mentors in schools before they graduate.

Chew and Andrews (2010) argue that a useful relationship between mentors and student teachers revolve around distributive leadership in which ownership and involvements are central. Such relationships allow student teachers to express themselves as individuals and exhibit a sense of shared purpose. By being allocated task that they carry out independently with mentor guidance, student teachers grow to be professionals who can make independent decisions.

In underlining the important role of the school-based mentor, McDonald (2004:85) states that:

\begin{abstract}
... an effective associate teacher needs to motivate student teachers, find out about their learning needs, discuss their perceptions about teaching and model effective teaching practice. ... should also provide regular feedback and ensure that their classroom is supportive of student supervision.
\end{abstract}

It is therefore important that mentors who work with student teachers in schools are properly prepared for their role. In a related study, Shumba, Shumba and Maphosa (2012) established that in most cases mentors were not trained for their roles as mentors. This underscores the significance of proper support between schools and universities in understanding mentoring and preparing mentors for their roles. Edward and Collinson (1995) assert that being a good or a senior teacher does not make one an effective mentor and Sanders (2000) contends that mentoring has a set of skills which have to be learnt and one requires training to be an effective mentor. Alberta Teachers' Association (ATA) (2003:10) advises that successful mentorship depends upon clarity of participant roles and responsibilities. According to ATA (2003), successful programmes have shown that mentors should continue to teach while serving as mentors as this will enable them to understand and appreciate challenges faced by mentees and assist them effectively.

It is clear from the above the fore going discussion that in teaching practice sessions there should be clarification on the roles of each mentor and student teachers. Student teachers must be well prepared for the actual world of work they are going to face. Other roles and responsibilities should be well communicated and guidelines must be provided to both the mentors and students. In underlining the importance of mentors an elementary principal cited in ATA (2003:19) expressed the importance of mentors when saying:

Because teaching is a new experience every time you walk into a classroom, good teachers build a repertoire of strategies and tools that they can use when they need them. Good mentors share their tools with their protégés and help them build their own repertoire.

The world is changing every day and so is the curriculum. Student teachers must be aware of the fact that teachers are implementers of any changes that might occur. In order to promote effective teaching and learning, mentors give student teachers opportunities to practice strategies and tools that they will use in their different context.

\title{
2. Theoretical Framework
}

The study is underpinned by the Situated Learning Theory which advances that learning is situated and that it happens within activity, context and culture. The study closely draws from what Lave and Wenger (1991) term "legitimate peripheral participation." In this view, knowledge should be presented in authentic contexts - settings and situations that would normally involve that knowledge. Social interaction and collaboration are essential components of situated learning - learners become involved in a "community of practice" which embodies certain beliefs and behaviors to be acquired. As the beginner or novice moves from the periphery of a community to its center, he or she becomes more active and engaged within the culture and eventually assumes the role of an expert. The same applies to student teachers working with mentors in schools as they move from periphery of professional expertise and are nurtured and developed until they become members of a community of practice. The nurturing and development of student teachers is done in real teaching 
and learning contexts. There should also be close collaboration between student teachers and senior professionals who guide them.

\title{
3. Research Context
}

The research was carried out in one School/Faculty in one rural based university in South Africa. The University offered a four-year Bachelor of Education degree for pre-service students. The Bachelor of Education curriculum included subject specialisation, foundations of education namely Sociology, Philosophy and Psychology of Education as well as History of Education. Students also studied pedagogy to enable them to teach in their areas and levels of specialisation. Students were also expected to do teaching practice. On teaching practice students worked under school-based mentors. University lecturers visited students on teaching practice to assess and grade them.

\section{Goal of the Study}

The study sought to assess the helpfulness of school-based mentors in the nurturing of student teachers' professional growth on teaching practice.

\section{Research Methodology}

Research paradigm: The study adopted a qualitative research paradigm. The researchers sought to understand better phenomenon under study as Lindlof (1995: 9) asserts that "qualitative inquirers strive to understand their objects of interest." Brown (2008:22) further states that:

\begin{abstract}
In contrast to quantitative research in which control and prediction of variables takes precedence by means of measurement and quantification, in qualitative research meaning and significance of themes takes precedence by means of first hand experiencing and participating.
\end{abstract}

The prime purpose of the present study was to establish from the participants' point of view the helpfulness of school-based mentors and visiting lectures in their professional growth hence a qualitative approach was found suitable. Such an intention is consistent with Krauss' (2005: 763) view that qualitative research 'has the unique goal of facilitating the meaning making'.

Research design: A case study design was utilised for this study. Yin (2003) cited in Neale, Thapa and Boyce (2006:3) states that:

\section{A case study is a story about something unique, special, or interesting - stories can be about individuals, organisations, processes, programs, neighbourhoods, institutions, and even events.}

The present study sought to hear student teachers' voices on the helpfulness of school-based mentors and visiting lecturers. Baxter and Jack (2008) further observe that case studies allow researchers to be close to research participants and allow the participants to tell their stories. The study was a case study of final year students in the Bachelor of Education degree programme who specialised in training to teach in the Foundation phase.

Sampling techniques: A purposive sample of twenty-five final year Bachelor of Education students specialising in Foundation Phase teaching participated in the study. Teddlie and Yu (2007: 77) observe that:

\footnotetext{
Purposive sampling techniques are primarily used in qualitative studies and may be defined as selecting units (e.g., individuals, groups of individuals, institutions) based on specific purposes associated with answering a research study's questions.
}

In the context of the present study, the participants selected had teaching practice experience as they were actually on teaching practice at the time the study was conducted. Thus the researchers targeted 'information-rich' sources in line with the purpose of the study. The sample consisted of twenty five students (twenty female and five male) and these were of varying age groups from nineteen to thirty- three.

Data collection tools: An open ended questionnaire was utilised to collect data from the participants. Choice of the use of an open ended questionnaire was justifiable in line with Ohman's (2005:275) view that qualitative questions are open-ended and allow "informants to tell their story." The researchers did not want to lead informants in any direction but 
sought to allow them to express themselves freely by simply narrating their experiences.

Data Analysis: Content analysis was used to analyse data. Analysis means extracting something systematically. Participants' responses were studied carefully and coded. According to Coffey and Atkinson (1996:32) 'codes are tools to think with.' Emerging patterns were drawn and themes highlighted. In content analysis, care was taken to 'let the text talk' without imposing meanings that were not in text (Graneheim \& Lundman, 2004: 113). Verbatim quotations were used extensively in this regard.

Trustworthiness: Elements of credibility, dependability and transferability were considered in ensuring trustworthiness of this qualitative study. To ensure credibility, the most appropriate method for data collection was selected. After analysing data, participants were asked to check for accuracy. Verbatim quotations and use of thick descriptions were used to ensure transferability of findings to other contexts whilst a thorough audit of the research process and findings ensured dependability.

Ethical issues: The researchers attended to all ethical issues consistent with the carrying out of social science research. Informed consent was sought from and granted by participants after the purpose of the study was explained to them. Confidentiality of participants' responses was guaranteed and participants were informed that their participation was voluntary and they could withdraw from the study at any stage and for whatsoever reason.

\section{Results}

\subsection{Helpfulness of school-based mentor}

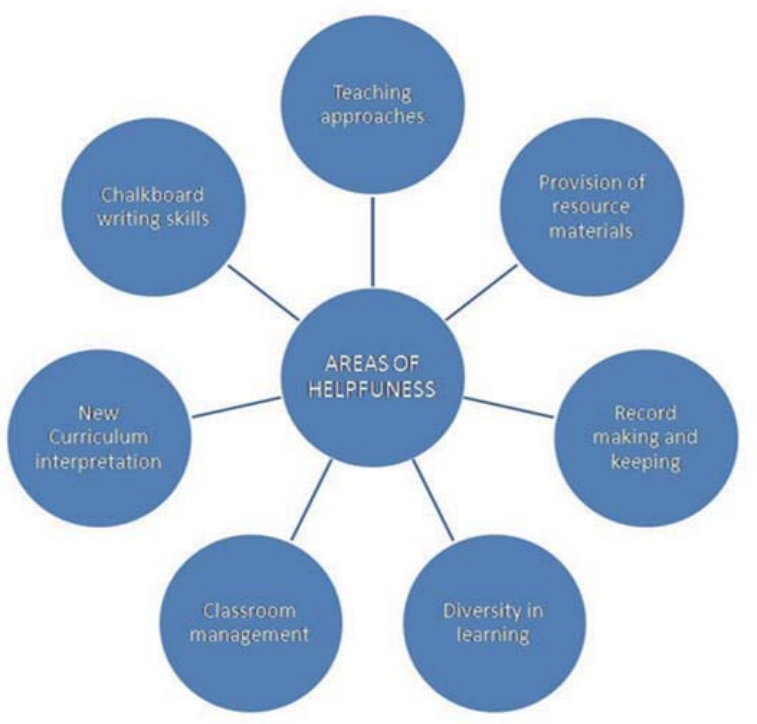

Figure 1: Summary of results.

\subsection{Teaching approaches}

Participants showed that their school-based mentors assisted them in the use of different teaching approaches as shown in the verbatim quotations below:

... the teacher showed me the way they taught learners. (QR 1)

She showed me different kinds of methods to use and how to use them (QR 2)

She taught me to involve all learners when teaching (QR 14)

She taught me to manage my time well when teaching (QR 21)

The above quotations confirm the helpfulness of mentors in giving direction regarding teaching approaches, which is very important in the professional development of a teacher. 


\subsection{Provision of resource materials}

It was also clear from the quotation below that participants revealed that mentors assisted in providing resources to mentees.

The teacher also gave me the resources they used in the class (QR 1)

She gave me the CAPS new curriculum document (QR 11)

She assisted me to make learning aids for my lessons (QR 13)

When I needed materials such as books she did not hesitate to give me (QR 23)

Providing resources necessary for the teaching work was confirmed as an area in which mentors ably assisted mentees.

\subsection{Record making and keeping}

Verbatim quotations below showed that participants were offered assistance in record making and record keeping.

She showed me how to make reports using recent rating scale (QR 1)

She showed me how to do a lesson plan and how to present it well in class (QR 2)

I was taught how to mark the class register (QR 2)

She taught me the importance of planning lessons (QR 4)

She taught me how to compile a work schedule (QR 9)

She encouraged me to keep my teaching portfolio up to date (QR 9)

Professional teachers are required to make and keep records regarding planning of their work and progress of students hence the importance of such kind of assistance.

\subsection{Diversity in teaching}

Participants also confirmed that they were assisted in dealing with diversity in classrooms as shown in quotation below:

She helped me a lot on how to deal with learners with different learning barriers (QR 2)

My mentor assisted me with ways to deal with children with emotional problems (QR 10)

She taught me to identify and assist learners with special needs (QR 24)

Dealing with student diversity is a prerequisite for a $21^{\text {st }}$ century teacher and it is therefore important for mentors top offer assistance in this regard.

\subsection{Demonstrating skills}

Participants also confirmed that mentors demonstrated skills in good teaching as shown in the quotations below:

She demonstrated and I observed while she worked with learners (QR 14)

She did not demonstrate good teaching (QR 19)

I copied her voice projection, speaking loudly so that all students could hear. (QR 16)

I observed her delivering a number of lessons (QR 17)

... she taught me how to write neatly on the chalkboard (QR 2) doing this.

The mentor is expected to show the way in terms of doing the right things and demonstrating is one sure way of

\subsection{Classroom Management}

Participants also revealed that they were assisted with classroom management skills as shown in excerpts below:

She showed me how to discipline those learners who always misbehaved in the classroom (QR3)

She taught me to place all misbehaving learners in font where I could see them (QR 3) 
Such assistance is important as no meaningful teaching and learning will take place if classrooms are not properly managed.

\subsection{New Curriculum Interpretation}

To improve the quality of teaching mentors are expected to guide student teachers on the implementation of the new curriculum. The following expressions serve as evidence:

My mentor assisted me in understanding the new CAPS curriculum (QR 18)

My mentor assisted me in preparing for observation by university lecturers (Q20)

She was interested in my good progress (QR 5)

The ability to deal with new curricula is an important attribute of a professional teacher as curricula often change in line with socio-economic and political changes.

\subsection{Feelings of negativity}

There were some negative sentiments on the issue of the helpfulness of school-based mentors as shown in excerpts below;

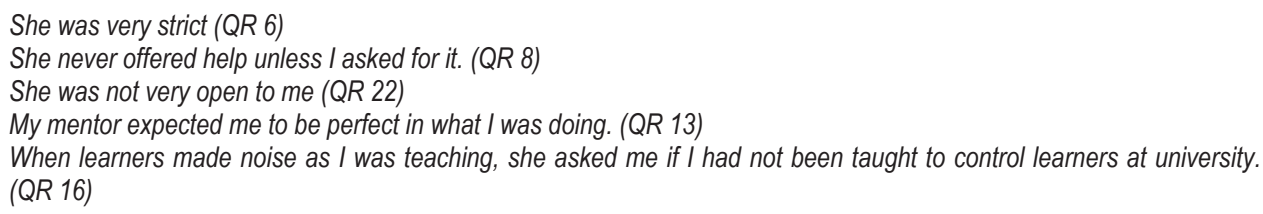

The above showed some challenges regarding the helpfulness of mentors as experiences by the participants.

\section{Discussion}

It emerged from the study that participants were assisted by their school-based mentors to apply effective teaching approaches. Such a finding is consistent with Joubert, Bester, Meyer and Evans' (2012) view that what is important is that teachers should be aware of the available teaching approaches and how and when to use them. In addition, the teacher must also know how to apply the strategy successfully in different contexts. Therefore the mentors believed it is critical that student teachers must be able to know and use different teaching approaches in order to address the learning needs of learners.

The study also established that mentors assisted in providing resources important for the execution of one's duties as a teacher. This finding is consistent with Ross, Vesco, Tricarico and Short's (2011) view that student teachers need skilled mentors who should provide student teachers with professional resources from textbooks, curriculum guidelines to pacing guides. Such materials enable mentees to do their work well because without the necessary 'tools for the job' it becomes very difficult to learn and perfect the art of teaching. It is therefore critical for trainee teachers to be provided with relevant resource materials in order to assist effectively facilitate learning in classrooms.

The study further established that school-based mentors assisted trainee teachers to deal with diversity in classroom in the true spirit of inclusive education. Professional teachers should be equipped and prepared to meet the needs of all learners as well as not only to provide equal opportunities for all learners but also education for an inclusive society. In the same vein, Reynolds (2001) is of the view that teachers' knowledge, beliefs and values are brought to bear in creating an effective learning environment for pupils. Teachers are therefore critical in influencing the promotion of diversity in teaching.

It further emerged from the study that school-based mentors demonstrated effective ways of performing teaching tasks. This finding confirms previous findings that point out the multiple gains and achievements that take place during mentoring and teaching practice (Arregui, Perez \& Garcia, 2009; Tillemma, 2000). Rose (2005:56) states that:

... the dialogue on shared experiences are more powerful and can take different forms: mentor and mentees can engage in team teaching or team planning, mentees can observe mentors, mentors can observe mentees, or both can observe other teachers. Regardless of the nature of the experience, the purpose is to promote collegial dialogue 
focused on enhancing teacher performance and student learning.

Therefore the mentor should model and demonstrate effective teaching strategies. Lieberman and Miller (2008) emphasises that student teachers benefit from becoming a part of community of learners in and environment where mentors model effective teaching behaviours in a relaxed manner.

It was also established in the study that school-based mentors assisted trainee teachers in dealing with classroom management. According to Alberta Teachers' Association (2003:22) mentors should help beginning teachers in classroom management by arranging the classroom setting; teaching rules; managing student work establishing a positive classroom climate and supporting good student behaviour in a true mentorship relationship. Callan (2006) stresses that the mentor offers the practitioner both organizational and personal strategies for handling the challenges, responsibilities, pressures and stresses of early years practice.

It emerged from the study that student teachers experienced challenges and feelings of negativity from mentors in some areas. Because of the complexity of teaching practice session the student teacher expressed the feeling of concern of not happy about the relationship. Crutcher (2007) advises that mentors should establish a collegial relationship with student teachers. A mentor should take interest in developing another person's career and well-being and also have an interpersonal as well as a professional relationship with those whom they mentor. Lick (1999) and Alred and Garvey (2000) stress that a special goal with mentoring is to contribute to learning. To make that happen the mentee, as the learner, ought to be engaged and have a constructive self-awareness.

\section{Conclusions}

It is concluded from the findings of the study that the mentor has a critical role in the professional development of teachers. It emerged from the study that most of the mentors were very helpful to their mentees. For example assisting the transmission of knowledge and skills; guiding the induction and nurturing of practitioners; linking theoretical models and philosophical approaches to practice and promoting shared good practice and professional values and focusing on the ability and potential of the practitioner. Participants also shared concerns on the helpfulness of some of the mentors.

\section{Recommendations}

Against the findings of the study, the following recommendations are made:

- Mentoring should be recognized as an activity concerned with the supported professional development of practitioners in work-based practice.

- The nature of mentoring should be determined by the 'culture' - traditions and philosophy of the institutions before the student teachers go for teaching practiced. This will to prepare them for the challenges coming in the way during teaching practice.

- Early years mentoring should be shaped by sector requirements as well as specific institutions and settings.

- Effective practice for mentors should be drawn on ethics and models of good practice established in teacher training contexts.

- Mentors should be shared with common characteristics and activities, whilst outcomes of the mentoring process will be context-specific.

- Mentors must reflect on their practice and will require a supportive and supported framework in which to do so.

- Feedback from student teachers regarding the problems faced by them in schools and should be considered important to improve the practice for next time.

\section{References}

Alberta Teachers' Association (ATA) (2003). Beginning Teachers' Handbook, Edmonton, Alberta, 2003. KU School of Education: http://www.soe.ku.edul. Accessed 20 December 2013

Alred, B., Garvey, G. (2000). Learning to produce knowledge: the contribution of mentoring. Mentoring and Tutoring 8 (3): 261 - 272

Arregui,E., Perez, R.P., Garcia, M.C.A. (2009). EL practicum desde una perspectiva de cambio Contextos Y Diagnosticos de estudiantes. Universidad Oviedo: Instituto Ciencias de la Education

Baxter, P., Jack, S. (2008). Qualitative case study methodology: study design and implementation for novice researchers. The Qualitative Report 13 (4): 544-549

Brown, S.R. (2008). Qualitative Methodology. In L.M. Given. The Sage Encyclopaedia of Qualitative Research Methods (p 700 - 704). 
Thousand Oaks, CA: Sage

Callan, S. (2006). Chapter 1: What is mentoring? www.sage.pub.com. Retrieved 6 January 2014.

Chew, J.O.A., Andrews, D. (2010). Enabling teachers to become pedagogical leaders: a case of two IDEAS schools in Singapore and Australia. Educational Research for Policy and Practice 9 (1): 59 - 74

Chubbuck, S.M., Clift, R. T., Allard, J., Quinlan, J. (2001). Playing it safe as a novice teacher, Implications for programs for new teachers. Journal of Teacher Education, 52 (5): 365-376

Coffey, A., Atkinson, P. (1996). Making Sense of Qualitative Data. Complementary Research Strategies. London: Sage Publications

Crutcher, B.N. (2007). Mentoring across cultures. Academe online. Retrieved September 2008 from www.aaup.org

Doherty, T.M. (1999). The role of mentors in the development of school principals. Unpublished doctoral dissertation, Virginia Polytechnic Institute and the State University.

Edwards, A., Collinson. J. (1995). What do teacher mentors tell student teachers about pupil learning in infant schools? Teacher and Teaching Theory and Practice 1 (2): 265 - 279

Fisher, T., Higgins, C., Loveless, A.M. (2006). Teachers Learning with Digital Technologies: A Review of Research and Projects. (Futurelab Series: Report 14). London: Futurelab

Graneheim, U.H., Lundman, B. (2004). Qualitative content analysis in nursing research: concepts, procedures and measures to achieve trustworthiness. Nurse Education Today 24, 105-112

Gray, W., Gray, M. (1985). Synthesis of research on mentoring beginning teachers. Educational Leadership, November pp 37-43

Groundwater-Smith, S. (1993). Introducing dilemmas into the practicum curriculum. Paper presented to the 5th National Practicum Conference. February 1993, Macquari University

Hansen, D.T. (2001). Exploring the Moral Heart of Teaching. New York: Teacher College Press

Joubert, I., Bester, M., Meyer, E., Evans, E. (2012). Literacy in the Foundation Phase. Pretoria. Van Schaick Publishers

Kiggundu, E., Nayimuli, S. (2009). Teaching practice: make or break phase for teachers. South African Journal of Education 29 (3):345 358

Koerner, M. (1992). The cooperating teacher: an ambivalent participant in student teaching. Journal of Teacher Education 43 (1): 46 - 56

Kram, K.E. (1983). Phases of the mentor relationship. Academy of Management Journal, 26 (4): 608-625

Krauss, S.E. (2005). Research paradigms and meaning making: a primer. The Qualitative Report 10 (4): 758 - 770

Lave, J., Wenger, E. (1991). Situated Learning: Legitimate Peripheral Participation. Cambridge: Cambridge University Press

Lick, D.W. (1999). Proactive Co-mentoring Relationships: Enhancing Effectiveness through Synergy. In C. A. Mullen \& D. W. Lick (Eds). New Directions in Mentoring: Creating a Culture of Synergy. (pp. 206-207).London: Falmer Press

Lieberman, A., Miller, L. (2008). Teachers in professional learning communities: improving teaching and learning. New York: Teachers College Press

Lindlof, T.R. (1995). Qualitative Communication Research Methods. Thousand Oaks, CA: Sage

Maphosa, C., Shumba, J., Shumba, A. (2007). Mentorship for students on teaching practice in Zimbabwe: Are student teachers getting a raw deal? South African Journal of Higher Education, 21(2): 296-307

McDonald, L. (2004). Effective mentoring of student teachers: attitudes, characteristics and practices of successful associate teachers within a New Zealand context. New Zealand Journal of Teachers' Work 1 (2): 85 - 94

Mel, P., Heller, N Sindelar, (1991). Developing an Effective Teacher Mentor Program Bloomington, Indiana: Phi Delta Kappa Educational Foundation

Neale, P., Thapa, S., Boyce, C. (2006). Preparing a Case Study: A Guide for Designing and Conducting a Case Study for Evaluation Input. Watertown, MA: Pathfinder International. http://www.pathfind.org/site/DocServer/m_e_tool_series_case_study.pdf ?docID=6302 Accessed 12 November 2013.

Ohman, A. (2005). Qualitative methodology for rehabilitation research. Journal of Rehabilitation Medicine 37 (5): 273 - 280

Reynolds, M. (2001). Education for Inclusion, Teacher Education and the Teacher Training Agency Standards Journal of In-Service Education 27(3):465-76

Rose, G.L. 2005. Group differences in graduate students' concepts of the ideal mentor. Research in Higher Education, 46(1), 53-80

Ross, D.D., Vesco, V., Tricarico, K., Short, K. (2011). Secrets for mentoring novice teachers. Gainesville,FL: Lastinger Center for Learning

Sanders, M. (2000). Increasing Associate Teacher Competence and Confidence. Tauranga: Bethlehem Institute of Education

Shumba, A., Shumba, J., Maphosa, C. (2012). Mentorship of student teachers on teaching practice: Perceptions of teacher mentors in Zimbabwean schools. Journal of New Generation Sciences 10 (1): 148 -169

Teddlie, C., Yu, F. (2007). Mixed Methods Sampling: A Typology With Examples. Journal of Mixed Methods Research 1 (1): 77-100

Tillemma, H. (2000). Belief change towards self-directed learning and student teachers: immersion in practice or reflection on action. Teaching and Teacher Education. 16:575-591

Timperley, H. (2008). Teacher Professional Learning and Development (Educational Practice Series 18) Geneva: International Bureau of Education

Vossler, K.R. (2006). Preparing teachers as professional educators: a new conception for pre-service teacher education. A thesis in partial fulfilment of the requirements for the degree of Doctor of Education at Mussey University, Palmerston North. New Zealand

Yin, R.K. (2003). Case Study Research: Design and Methods. Thousand Oaks, CA: Sage 